\title{
Penempelan Larva Siput Laut (Haliotis varia) : Suatu Percobaan di Laboratorium
}

\author{
Settlement Larvae of Abalone (Haliotis varia) : A Laboratory Experiment \\ Medy Ompi*, Nickson Kawung, dan Calvyn, F.A. Sondak \\ Laboratory Biologi Kelautan, Fakultas Perikanan dan Ilmu Kelautan \\ University Sam Ratulangi, Manado, Kampus-Bahu 95115, Sulawesi Utara \\ Email: ompimedy@yahoo.com; ompimedy@unsrat.ac.id, *penulis untuk korespondensi
}

\begin{abstract}
Settlement of abalone (Haliotis varia) focusing on substrate quality and larval behavior were studied. Four types of substrate, shell and mucous, algae Gracilaria sp and Halimeda sp, and plastic petri-dish were used to test whether the larva might respond and settle on those substrates. At the same time, the mortality of larvae was also determined during the settlement. Without petri-dish, substrate of shell and mucous, algae, as well as polyvinyl chloride (PVC) plate were tested to find out substrate preferences when settlements occured. The result showed that variation of substrata, shell and mucous, algae and plastic "petri-dish" possessed a stimuli responded by larva to settle. Shell and mucous as well as substrate algae were attractive among of substrata, since high of settlement on it were recorded. High larval mortality on shell and mucous as well as on substrata of algae were recorded. Substrate of shell and mucous and alga were favorable to substrata when settling. Several factors affecting settlement of larval abalone were discussed.
\end{abstract}

Key words: Larva, settlement, metamorphosis, mortality, substrate, abalone

\begin{abstract}
Abstrak
Penelitian penempelan larva siput laut (Haliotis varia) yang difokuskan pada kualitas substrat dan tingka laku larva telah dilakukan. Ada empat jenis substrat, yaitu cangkang dan mukus, alga Gracilaria sp dan Halimeda sp, dan cawan petri, yang digunakan untuk menguji apakah larva siput laut dapat merespon dan menempel pada keempat substrat tersebut. Secara bersamaan, mortalitas larva juga diamati selama penempelan. Tingkah laku memilih kesukaan substrat pada penempelan diuji dengan menyediakan substrat cangkang dan mukus, alga, dan "plate polyvinyl chloride". Hasil penelitian menunjukkan bahwa keempat jenis cangkang bersama mukus dari induk siput abalone, alga Gracilaria sp dan Halimeda sp memiliki rangsangan yang direspon oleh larva dengan penempelan pada keempat substrat ini. Substrat cangkang dan mukus serta alga adalah substrat yang direspons dengan baik yang ditandai dengan tingginya jumlah penempelan larva. Tingginya mortalitas larva siput laut nampak yang menempel pada substrat cangkang dan mukus serta alga. Larva siput laut memiliki tingkah laku memilih substrat di saat menempel, di mana substrat cangkang dan mukus serta alga adalah menjadi substrat kesukaannya. Beberapa faktor yang memengaruhi penempelan larva siput laut didiskusikan pada pembahasan.
\end{abstract}

Kata kunci: Larva, penempelan, metamorphosa, mortalitas, substrat, siput laut

Diterima: 17 Juli 2010, disetujui: 21 September 2010

\section{Pendahuluan}

Tahap yang sangat krusial dalam suatu siklus hidup bagi invertebrata dasar laut termasuk siput laut (Haliotis varia) adalah saat organisme berada dalam tahap "settlement" dan "metamorphosis". "Settlement" diartikan sebagai tahap keberadaan larva pada fase akhir yang berada di kolom perairan, kemudian turun ke dasar, berenang dan berguling di dasar mencari substrat kesukaannya untuk tinggal dan menetap, sedangkan metamorfosis adalah suatu fase perubahan baik morfologi, fisiologi, dan substrat (Hahn, 2000). Baik "settlement" maupun 
metamorfosis dikategorikan sebagai tahap penempelan (Ompi et al., 2010), pada tahap ini dikenal sebagai fase transisi di dalam suatu siklus hidup bagi umumnya organisme invertebrata yang hidup di dasar laut. Larva yang dapat melewati fase transisi ini memiliki kemampuan hidup lebih baik dibandingkan larva yang masih berada pada fase transisi. Misalnya tingkat kematian larva yang telah menempel lebih rendah daripada larva yang masih dalam proses penempelan (Widdows, 1991 dan Chia, 1989).

Sukses tidaknya "settlement" dan metamorfosis ini akan banyak tergantung baik pada ketersedian substrat dan tingkah laku larva. Menemukan substrat yang cocok adalah sebagai aktivitas yang utama bagi kebanyakan larva invertebrata dasar laut, di saat larva dikategorikan kompeten untuk turun ke dasar dan kemudian bermetamorfosis. Namun, kondisi alam seperti arus dan gelombang yang kuat, dapat menghilangkan kemampuan larva untuk menemukan substrat yang dimaksud. Larva yang mencari dan menemukan substrat yang cocok. Selanjutnya, dapat menyelesaikan metamorfosis. Larva kembali berenang ke kolom perairan, ataupun akan menolak metamorfosis, jika substrat yang tersedia adalah tidak cocok (Ompi, 2006; Boxshall, 2000). Siput laut (H. varia) ditemukan melekat pada celah ataupun lubanglubang substrat karang mati, batuan, mikrofilm alga, jenis-jenis alga termasuk 'coralline' alga, dan makro alga lainnya juga menempati habitat yang sama dengan siput ini (Ompi dan Ronoko, 2006). Namun, kemampuan tipe dan jenis substrat ini dapat merangsang larva untuk turun ke dasar dan metamorfosis masih dipertanyakan. Substrat termasuk induk siput memiliki karakter baik fisik, biologi, kimia yang dapat merangsang larva untuk turun ke dasar dan metamorfosis (Zahida et al., 2005).

Ragam substrat dipahami dapat mengstimulasi larva untuk turun ke dasar, menempati substrat, dan metamorfosis. Sebagai contoh, larva Mytilus galloprovincialis yang menempel pada substrat yang bercampur dengan lendir induknya (Martinez et al., 1994). Larva kerang mutiara Pinctada maxima menempel pada cangkang kerang dan tali rafia (Ompi et al., 2010), dan larva siput laut yang hidup di perairan dingin, Haliotis rufescens, yang menjadikan mikro algae dan bakteri, sebagai substrat kesukaan untuk penempelan (Boxshall, 2000). Namun, merespons stimulan yang datang dari substrat dapat bervariasi bahkan cenderung tidak konsisten untuk setiap jenis larva. Misalnya, diatom dan juga mukus dari induk dapat merangsang beberapa jenis larva seperti pada larva siput laut $H$. discus hannai, tetapi tidak untuk jenis larva siput laut lainnya (Morse dan Morse, 1984). Larva siput H. discus hannai memilih substrat kesukaan saat penempelan, tetapi pola tingkah laku ini tidak dimiliki oleh larva $H$. rufescens, yang menolak untuk menempati substrat yang ditempati oleh larva $H$. discus hannai (Slatery, 1992).

Informasi penempelan larva siput laut jenis $H$. varia adalah sangat terbatas. Pertanyaannya, (1) bagaimana pengaruh substrat selama fase penempelan larva siput $H$. varia?, (2) adakah kesukaan substrat (susbtrate preferences) dari larva siput ini selama fase penempelan? Tujuan penelitian ini adalah untuk memahami tingkah laku larva siput laut $H$. varia selama penempelan, lebih khusus: (1) mempelajari penempelan serta mortalitas larva siput dalam merespon kehadiran substrat baik cangkang serta mukus (lendir), alga Gracilia sp, alga Halimeda sp, dan plastik cawan petri, dan (2) mempelajari adanya kesukaan atau tidak, terhadap substrat yang tersedia.

\section{Metode Penelitian}

\section{Pengambilan Sampel}

Induk siput laut $(H$. varia) diambil dari perairan Tiwoho (Minahasa Utara), Buha dan Mokupa (Kabupaten Minahasa), selama penelitian yaitu pada bulan April-Oktober 2008. Siput dipisahkan dengan hati-hati dari substratnya, kemudian di masukkan ke dalam kantong jaring, dan di bawa ke Laboratorium Biologi Kelautan, Fakultas Perikanan dan Ilmu Kelautan, Unsrat, sebagai tempat pemijahan dan fertilisasi.

\section{Pemijahan dan Fertilisasi}

Induk siput laut jantan dan betina dipilih yang matang gonad, mengikuti metode Hahn (2000). Jantan dan betina yang dipilih secara bersama-sama dimasukkan ke dalam wadahwadah akuarium yang berisi 10 liter air laut yang 
telah disaring $(0,5$ dan $1 \mu \mathrm{m})$. Aerasi yang kuat diberikan pada wadah penampung ini, dengan tujuan untuk memberikan stress pada induk agar terangsang untuk memijah (Sarida, 2008). Siput laut masing-masing satu jantan dan betina dipindahkan dan dimasukkan pada akuarium yang berisi 5-10 liter air laut yang terlebih dahulu telah disaring pada jam 20.30 malam. Siput laut merespons perlakuan setelah beberapa jam setelah dipindahkan, yaitu betina melepaskan telur yang berwarna hijau kehitaman dan jantan melepaskan sperma yang berwarna keputihan. Telur dan sperma dibiarkan dalam wadah ini hingga fertilisasi, dan terbentuk larva.

\section{Larva}

Telur yang terfertilisasi dan mencapai fase larva dipisahkan dengan menggunakan saringan, berdiameter $80 \mu \mathrm{m}$ pada besok harinya. Larva "trochopore" kemudian dipelihara pada wadah yang tersedia baik di akuarium dan ember dengan volume 25 dan 50 liter, dengan kepadatan 5 larva per ml (Strathmann dan Fernald, 1992). Larva berada di wadah-wadah pemeliharaan ini sampai mencapai larva "pediveliger", yaitu larva yang telah mencapai fase yang kompeten untuk turun ke dasar dan menempel (Hahn, 2000). Larva "pediveliger" ini adalah larva yang digunakan dalam percobaan.

\section{Ekperimen Respon Larva pada Subtrat}

Enam belas cawan petri dengan diameter 4 $\mathrm{cm}$, disiapkan untuk mendistribusikan empat jenis yaitu mukus dan cangkang, "coraline algae" (Halimeda sp), dan alga merah (Gracilaria sp), ditambah dengan substrat kontrol (cawan petri tanpa substrat). Masing-masing substrat, termasuk kontrol, memiliki 4 ulangan cawan petri, sebagai replikasi. Semua cawan petri terlebih dahulu telah direndam di sistem sirkulasi air laut selama seminggu sebelum digunakan, untuk menghilangkan bau plastik cawan petri.

Satu individu siput dewasa diletakkan di atas masing-masing satu cawan petri, yang terlebih dahulu telah diintroduksi dengan cangkang. Siput dibiarkan di atas cawan petri untuk beberapa jam sampai lendir ataupun mukus siput menutup setengah atau kira-kira 2 $\mathrm{cm}^{2}$ dari dasar cawan petri. Alga Halimeda dan Gracilia dicuci beberapa kali dengan menggunakan air laut, kemudian dimasukkan ke dalam cawan petri, menutup kira-kira $2 \mathrm{~cm}^{2}$ dasar petri. Kemudian, tiap-tiap cawan petri dimasukan $5 \mathrm{ml}$ air laut yang telah difilter. Larva yang kompoten untuk 'settle' dimasukkan ke tiap-tiap cawan petri dengan kepadatan 2 larva per ml. Semua cawan petri diletakkan pada ruangan yang tidak ada cahaya dengan kontrol suhu $28^{2}-29^{\circ} \mathrm{C}$.

Pengamatan dilakukan setelah 24 jam setiap cawan petri diletakan di bawah lensa 'dissecting' mikroskop. Larva ada yang berenang dan ada yang di dasar petridish. Larva yang di dasar petri dikategorikan sebagai larva yang "settle" (menempel) dan metamorphosis (Hahn, 2000). "Cilia" berupa rambut-rambut yang terlepas, serta kaki adalah beberapa karakter "pediveliger" siput laut yang menempel pada substrat dan metamorphosis (Hahn, 2000).

\section{Kesukaan Substrat (Substrate preferences)}

Substrat yaitu mukus dan cangkang, "coraline algae" (Halimeda sp), dan alga merah (Gracilaria sp), temasuk kontrol, tiap-tiap dengan 3 ulangan, didistribusikan secara random pada 12 ruang kuadrat persegi, tiap-tiap ruang memiliki luas $1,5 \mathrm{~cm}^{2}$. Ruang kuadrat persegi ini dibuat pada "plate PVC" (polyvinyl chloride) yang ukuran $7 \times 7 \mathrm{~cm}$. Ada 9 lobang dengan diameter $1 \mathrm{~cm}$ yang dibuat di tengah-tengah pada tiap-tiap ruang kuadrat persegi ini. Tiga ruang quadrat persegi lainnya dibiarkan tanpa lobang, sebagai kontrol. Jenis substrat (mukus dan cangkang, alga karang (Halimeda sp), dan alga merah (Gracilaria sp), masing-masing dengan ulangannya, ditekan dan dimasukkan pada lobang yang telah tersedia. PVC dengan perlakuannya kemudian dimasukan ke dalam paralon dengan diameter $12 \mathrm{~cm}$ dan tinggi $7 \mathrm{~cm}$, yang dasar paralonnya telah ditutup dengan jaring, dengan diameter mata jaring $100 \mu \mathrm{m}$.

Ada dua paralon yang dibuat, masingmasing diisi dengan "plate PVC" yang telah ada perlakuan. Kedua paralon ini diletakkan pada rak di dalam suatu sistem sirkulasi air laut. Sistem sirkulasi air laut ini terdiri dari 2 plastik kontainer persegi panjang, masing-masing berukuran $50 \mathrm{~cm}$ X $30 \mathrm{~cm}$ X $10 \mathrm{~cm}$. Satu kontainer dilengkapi dengan rak, yang memiliki kaki yang memungkinkan untuk mengatur ketinggiannya, agar sesuai dengan tinggi rendahnya air laut yang ada di dalam kedua 
paralon yang ditempatkan pada sistem rak ini. Plastik kontainer lainnya dilengkapi dengan pompa sirkulasi air laut dengan volume rendah. Kedua kontainer ini disusun berlapis dengan bantuan sistem rak juga. Kontainer yang dilengkapi dengan pompa untuk sirkulasi air laut diletakkan di dasar. Kontainer di dalamnya dilengkapi dengan rak yang ditempati oleh kedua paralon, ditempatkan di atasnya. Air laut dari kontainer plastik di dasar, akan dipompa melalui koneksi pipa plastik ke kontainer di atasnya yang dilengkapi dengan rak serta perlakuan percobaan. Selanjutnya, air laut ini juga dibuang melalui pipa plastik buangan ke kontainer yang dilengkapi dengan pompa sirkulai. Sistem sirkulasi air laut ini dimodifikasi dari Strathmann dan Fernald (1992).

Air laut yang masuk di dalam paralon diatur sampai pada ketinggian $5 \mathrm{~cm}$. Kedua paralon, masing-masing dengan perlakuannya, dikategorikan sebagai percobaan 1 dan 2 . "Pediveliger" (20 larva) dimasukkan ke dalam setiap paralon, kemudian dibiarkan selama 24 jam dalam wadah ini. Di akhir percobaan ini, 'pediveliger' yang masih berenang dipindahkan dengan memipet dan dimasukkan pada "pirex glass", sedangkan PVC plate diangkat secara perlahan-lahan dari paralon, kemudian larva yang menempel diamati dan dihitung dengan menggunakan disekting mikroskop.

\begin{abstract}
Analisis Data
Data penempelan sebagai akibat respons larva pada substrat dianalisis dengan menggunakan ANOVA satu arah. Analisis yang sama juga digunakan untuk menganalisis data persentase "mortalitas" saat menempel sebagai respons terhadap substrat yang tersedia. ANOVA satu arah juga digunakan untuk analisis kesukaan substrat. Data terlebih dahulu telah diuji ke 'homogenety variance'nya (Fowler et al., 1998), sebelum dilanjutkan dengan uji ANOVA. Uji lanjutan pada saat adanya pengaruh perlakuan dilakukan dengan menggunakan SNK-test.
\end{abstract}

\section{Hasil dan Pembahasan}

\section{Respon Larva pada Substrat}

Larva siput laut turun ke dasar dan menempel sebagai respons terhadap adanya substrat yang beragam, baik substrat alga Gracilaria sp, Halimeda sp, cangkang bersama 'mukus', dan cawan petri sebagai kontrol, yang ditampilkan pada Gambar 1. Larva tampak berenang, bergulir pada substrat, ataupun menempati substrat saat dipaparkan pada substrat yang tersedia.

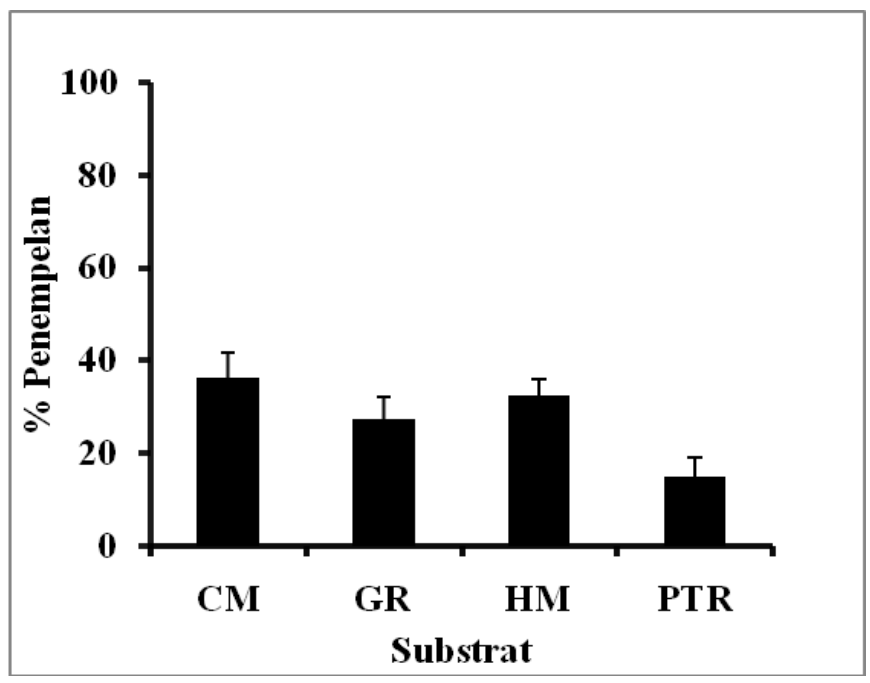

Gambar 1. Rata-rata penempelan pediveliger siput laut, sebagai respons terhadap substrat yang berbeda, $\mathrm{CM}=$ cangkang serta mukus, $\mathrm{GR}=$ alga Gracilaria sp, HM=alga Halimeda sp, dan PTR=Petri dish (cawan petri), (Error Bar=Standar Error 95\%). 
Pola penempelan "pediveliger" siput laut pada substrat cangkang serta "mukus" dan alga lebih tinggi dibandingkan dengan substrat cawan petri (kontrol). Pola penempelan ini sesuai dengan analisis statistik yang memperlihatkan bahwa penempelan "pediveliger" dipengaruhi oleh kehadiran jenis substrat yang tersedia $(\mathrm{P}<0,05 ;$ Satu Arah ANOVA), seperti diperlihatkan pada Tabel 1.

Banyak faktor berperan dalam "membawa" larva turun ke dasar pada saat penempelan, seperti tingka laku larva, ketersedian substrat, predator, makanan, kondisi lingkungan seperti hidrodinamik, suhu, dan salinitas (Wildish dan Kristmanson, 1997; Zardus dan Martel, 2002; Ompi et al., 2010; Zahida et al., 2005), dalam penelitian ini difokuskan ketersedian substrat dan tingkah laku larva di saat penempelan. "Pediveliger" siput abalone tampak terangsang dengan kehadiran substrat, yang secara konsisten merespon dengan menempel pada substrat cangkang dan mukus dengan persentase yang relatif lebih besar dibandingkan dengan substrata lainnya. "Pediveliger" tampak juga terangsang dan menempel secara konsisten dengan jumlah ratarata persentase relatif lebih besar dengan kehadiran substrat alga baik Gracilia sp dan Halimeda sp dibandingkan dengan kehadiran substrat cawan petri, sebagai kontrol.

Kondisi biologi dan fisik substrat dapat menjadi faktor yang direspon oleh larva, turun ke dasar dan menempel. Komponen dari induk seperti cangkang dan "mukus" direspons oleh pediveliger siput, $H$. varia, dengan turun ke dasar dan menempel. Pola ini menjadi karakteristik beberapa jenis larva invertebrata laut, seperti "pediveliger" abalone sub-tropis, Haliotis rufescens (Bernal et al., 1992) dan kerang mediterania, Myilus galloprovincialis (Martinez et al., 1994). Kondisi fisik "thalus" dan perbedaan warna alga, direspons oleh larva dengan menempel pada substrat ini (King et al., 1990). Alga Halimeda sp tumbuh di substrat karang dan alga merah Gracilaria sp dengan kandungan alginnya (Ismail, 1995; Wei dan Chin, 1983), yang kemungkinan dapat memberikan respons berbeda oleh larva siput laut untuk turun ke dasar dan menempel.

Karakter substrat licin kemungkinan sebagai salah satu yang menyebabkan rendahnya respons larva menempel pada substrat ini. Larva cenderung terus berenang, turun ke dasar mencari substrat dan kembali ke kolom perairan saat ketersediaan substrat relatif tidak sesuai, seperti juga ditunjukkan oleh beberapa jenis invertebrata laut yang dilaporkan oleh Widows (1993) dan Ompi et al., (2010).

\section{Mortalitas}

Larva siput abalone nampak memiliki persentase (\%) tingkat kematian (mortalitas) yang bervariasi saat penempelan sebagai respon terhadap substrat yang tersedia. Pola persentase mortalitas "pediveliger" yang menempel relatif lebih tinggi pada substrat cangkang dan alga dibandingkan dengan yang menempel sebagai respons pada cawan petri tanpa substrat (Gambar 2). Namun, pola ini tampak berbeda dengan hasil analisis statistik, persentase mortalitas pedeveliger siput laut di saat menempel tidak dipengaruhi oleh perlakuan substrat $(\mathrm{P}>0,05$; Satu Arah ANOVA), seperti ditunjukkan pada Tabel 2.

Penempelan dikategorikan sebagai tingkat yang lebih kritis dibandingkan dengan fase lainnya dalam suatu siklus hidup umumnya invertebrata dasar laut (Martinez et al., 1994). Bentuk dan organ selama fase ini akan berubah, misalnya bentuk tubuh yang sama dengan induk biota pada saat menempel, kemudian terlepasnya cilia dan terbentuknya kaki di akhir dari fase larva (Zardus dan Martel, 2002). Larva turun ke dasar dan mencari substrat untuk menempatinya sebagai respons terhadap kehadiran substrat, banyak larva yang mengalami kegagalan dalam menyelesaikan perubahan selama penempelan, yang menyebabkan tingginya persentase kematian bagi larva yang berada pada fase ini, termasuk juga larva abalone yang menempel pada substrat cangkang serta "mukus" dan juga pada substrat alga.

Larva yang kembali berenang ke kolom perairan akan membutuhkan energi yang cukup untuk menopang aktivitas ini (Videla et al., 1998). Sumber energi larva invertebrata laut berasal dari kandungan telur, dan selama larva tidak lagi ada penambahan energi baru, seperti umumnya larva abalone (Hahn, 2000), maka kembali ke kolom perairan adalah salah satu yang akan menyebabkan kegagalan hidup dari larva. 


\section{Substrat Kesukaan}

Adanya pola pemilihan substrat oleh larva siput abalone saat penempelan, diperlihatkan pada Gambar 3. Larva siput abalone yang menempel pada substrat cangkang dengan mukus dan alga tampak secara konsisten relatif lebih banyak dibandingkan dengan "pediveliger" yang menempel pada substrat lainnya. Pola ini memperlihatkan bahwa larva abalone secara biologi akan memilih substrat saat penempelan, yaitu pada substrat cangkang dengan mukus dan alga. Walaupun dalam uji statistik menunjukkan bahwa penempelan "pediveliger" abalone dipengaruhi oleh substrata hanya ditunjukkan pada percobaan I $(\mathrm{P}<0,05$, Uji Satu Arah ANOVA) dan tidak tampak pada percobaan II (P>0,05, Uji Satu Arah ANOVA, Tabel 3). Khusus untuk percobaan I, uji lanjut dilakukan terhadap data penempelan, menunjukkan ratarata persentase penempelan secara nyata lebih tinggi pada substrat cangkang dengan mucus dan alga dibandingkan dengan penempelan pada substrat plate $(\mathrm{PVC})$ yang rata $(\mathrm{P}<0,05, \mathrm{SNK}-$ test). Plate PVC bukan sebagai substrat kesukaan, yang tampak dari rendahnya penempelan larva pada substrat ini I dan II (Gambar 3).

Banyak faktor yang dapat menentukan penempelan larva saat turun ke dasar dan memilih kesukaan substrat, di antaranya kondisi fisik, biologi, dan kimia dari substrat (Chia, 1989; Zardus dan Martel, 2002). Dalam penelitian ini tampak kondisi biologi dan fisik dari substrat adalah sangat memengaruhi pemilihan substrat. Secara biologi, cangkang dengan mukus adalah bagian yang diproduksi induk dewasa, yang dapat mendorong larva ini untuk menempel pada substrat ini. Pola penempelan pada substrat yang berhubungan dengan induk adalah faktor yang mendorong beberapa jenis larva untuk menempel, larva siput abalone sub-tropis Haliotis rufescens (Slatery, 1992)dan larva kerang Mytilus galloprovinciallis (Martinez et al., 1994). Substrat yang beragam bentuk, seperti pada alga (semacam daun dan semacam batang) dalam penelitian ini, adalah kemungkinan sebagai salah satu bentuk fisik yang juga telah menjadi salah satu faktor yang mendorong larva $H$. varia untuk turun ke dasar dan menempel pada substrat ini, ragam fisik ini juga telah menjadi pilihan bagi beberapa jenis larva invertebrata sebagai substrat kesukaannya saat penempelan (King et al., 1990).

Kehadiran organ mata dan kaki akan memungkinkan larva siput abalone untuk memilih susbtrat. Kaki larva kemungkinan dapat menguji kesesuaian substrat, sehingga larva abalone memilih dan tinggal pada substrat itu (Hahn, 2000). Larva dapat bergulir pada substrat dan menguji kesesuain substrat termasuk kemungkinan dalam pemilihan substrat kesukaan seperti "pediveliger" abalone sub-tropis, Haliotis rufescens (Bernal et al., 1992), dan beberapa jenis "pediveliger" bivalve, Brachidontes erosus dan Trichomya hirsutus (Ompi, 2005).

Tabel 1. Satu Arah ANOVA, Substrat sebagai Faktor Utama.

\begin{tabular}{llllcc}
\hline \hline \multicolumn{1}{c}{ Source } & df & SS & MS & F & P \\
\hline Substrata & 3 & 21,688 & 7,229 & 3,899 & 0,037 \\
Residu & 12 & 22,250 & 1,854 & & \\
\hline \hline
\end{tabular}

Tabel 2. Satu arah ANOVA, untuk Uji Mortalitas, dengan Substrat sebagai Faktor Utama.

\begin{tabular}{llllll}
\hline \multicolumn{1}{c}{ Source } & df & SS & MS & F & P \\
\hline \hline Substrata & 3 & 2958,3 & 986,4 & 5,917 & 0,199 \\
Residu & 8 & 1333,33 & 166,607 & & \\
\hline \hline
\end{tabular}


Tabel 3. Satu Arah ANOVA, untuk Uji Penempelan dengan Substrat sebagai Faktor Utama, Baik pada Percobaan I dan II.

\begin{tabular}{|c|c|c|c|c|c|}
\hline Source & df & SS & MS & $\mathbf{F}$ & $\mathbf{P}$ \\
\hline \multicolumn{6}{|c|}{ Percobaan I } \\
\hline Substrata & 3 & 5,976 & 1,99 & 4,058 & 0,05 \\
\hline Residu & 8 & 3,927 & 0,49 & & \\
\hline \multicolumn{6}{|c|}{ Percobaan II } \\
\hline Substrata & 3 & 3,116 & 1,04 & 2,238 & 0,16 \\
\hline Residu & 8 & 3,710 & 0,46 & & \\
\hline
\end{tabular}

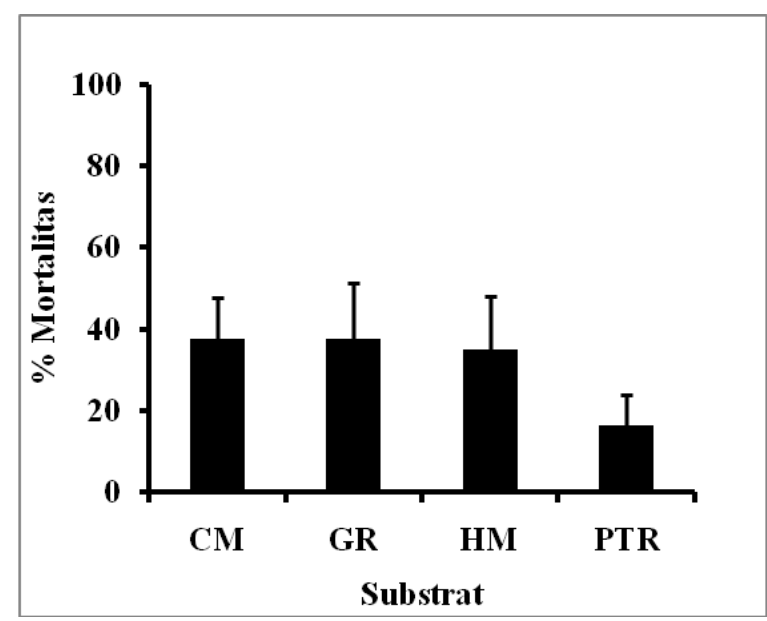

Gambar 2. Rata-rata mortalitas (\%) pediveliger abalone saat penempelan, sebagai respons terhadap substrat yang berbeda, CM=cangkang serta mucus, GR=alga Gracilaria sp, HM=alga Halimeda sp, dan PTR=petri dish (Cawan Petri), (Error Bar=Standar Error, 95\%).
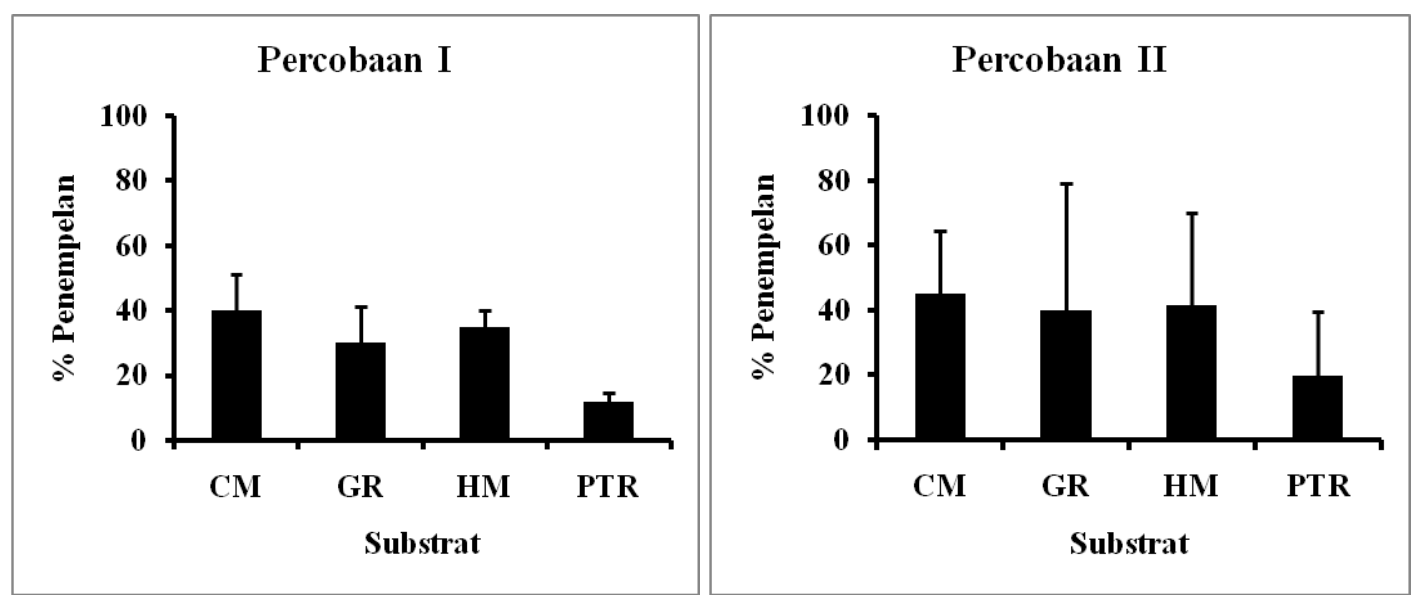

Gambar 3. Rata-rata persentase penempelan pediveliger Abalone pada substrat yang berbeda, baik pada Perobaan I dan Percobaan II. CM=cangkang serta mukus, GR=alga Gracilaria sp, HM=alga Halimeda sp, dan PTR=Plate PVC. (Error Bar=Standar Error, $95 \%$ ).

\section{Simpulan}

Larva siput laut memiliki tingkah laku memilih substrat kesukaan, yaitu cangkang dengan mukusnya dan alga. Peningkatan jumlah penempelan pada substrat, diikuti dengan tingginya tingkat kematian larva siput abalone pada substrat. 


\section{Ucapan Terima Kasih}

Penelitian ini didanai melalui penelitian dasar dengan kontrak nomor: 031/SP2H/PP/ DP2M/III/2008. Untuk itu, terima kasih disampaikan kepada DIKTI, melalui Lembaga penelitian Unsrat yang telah mendukung penelitian ini.

\section{Daftar Pustaka}

Boxshall, A. 2000. The Importance of Flow and Settlement Cues to Larvae of The Abalone, Haliotis rufescens Swainson. J. Exp. Mar. Biol. and Ecol., 254: 143-167.

Bernal, R.S., Salas-Garza, A.E., Flores-Aguilar, R.A. dan Hinojosa-Rivera, P.R. 1992. Simulatneous Comparison of Methods for Settlement and Metamorphosis Induction in The Red Abalone (Haliotis rufescens). Aquaculture, 105: 241-250.

Chia, F. 1989. Differential Larval Settlement of Benthic Marine Invertebrates. In: Ryland, J.S. \& Tyler, P.A. (Eds.). Reproduction, Genetic and Distributions of Marine Organisms. Proc $23^{\text {rd }}$ Eur Mar Biol Symp, Olsen \& Olsen, Fredensborg: 3-12.

Fowler, J., Cohen, L. dan Jarvis, P. 1998. Practical Statistics for Field Biology. Second Edition. Wiley.

Hahn, O. 2000. Induction of Settlement in Competent Abalone Larva. CRC Handbook of Culture of Abalone and other Marine Gastropods. CRC Press, Florida. 101-112.

Ismail, L.H. 1995. Rumput laut Malaysia. Dewan Bahasa dan Pustaka. Ampang/Hulu Kelang. 277 p.

King, P.A., Mcgrath, D. dan Britton, W. 1990. The use of Artificial Substrates in Monitoring Mussel (Mytilus edulis L.) Settlement on an Exposed Rocky Shore in the West of Ireland. J. Mar. Boil. Ass., 70: 371-380.

Martinez, J.C., Robledo, J.A.F. dan Figuereas, A. 1994. Settlement dan Post Larval Behaviour of Mytilus galloprovinciallis: Field and Laboratory Experiments. Mar. Ecol. Prog., 112: 107-117.

Morse, A.N.C. dan Morse, D.E. 1984. Recruitment and metamorphosis of Haliotis larvae induced by molecules uniquely at the surface of Crustoce red algae. J.Exp. Mari.Biol. Ecol., 75: 191-215.
Ompi, M. 2005. Larval Settlement of Mytilus galloprovincialis (Lamarck, 1819) and Trichomya hirsutus (Lamarck, 1819). J. Perikanan dan Ilmu kelautan, 1 (2): 1411-9234.

Ompi, M. 2006. The Reproductive Patterns of Two South Australian Mytilids Species: Brachidontes erosus (Lamarck, 1819) and Brachidontes rostrtus (Dunker, 1857). Biota, 21: 116-122.

Ompi, M. dan Ronoko, S. 2006. Survei Populasi Siput Haliotis varia di Pantai Tiwoho dan Utara Bunaken. Paper. Fakultas Perikanan dan Ilmu Kelautan, Universitas Sam Ratulangi. Manado.

Ompi, M., Sampekalo, J. dan Tomatala, P. 2010. Penempelan Larva Kerang Mutiara (Pinctada maxima, J) di Laboratorium Pt Sikoa, Provinsi Maluku. J. Pacific, 1 (5): 734-737.

Sarida, M. 2008. Studi Embriogenesis dan Perkembangan Larva Abalone Mata Tuju (Haliotis asinine Lin. 1758). Prosiding, Unila. Pp. 330-336.

Slatery, M. 1992. Larval Settlement and Juvenile Survival in Red Abalone (Haliotis rufescens): an Experiment of Inductive Cues and Substrate Selection. Aquaculture, 102: 143-153.

Strathman, M.F. dan Fernald, R.L. 1992. Reproductive and Development of Marine Invertebrates of the Northern Pacific Coast. University of Washington, Press. Seattle and London.

Videla, J.A., Chaparro, O.R. dan Thompson, R.J. 1998. Role of biochemical energy serve in the metamorphosis and early juvenile development of the oyster Ostrea chilensis. Marine Biology, 132: 635-640.

Wildish, D. dan Kristmanson, D. 1997. Bentik Suspension Feeders and Flow. Cambrige University Express. Melbourne - New York. 127 p.

Widdows, J. 1991. Physiological Ecology of Mussel Larvae. Aquaculture, 94: 147-163.

Wei, T.L. dan Chin, W.Y. 1983. Seaweeds of Singapore. Singapore University Press. Singapore. 123 p.

Zahida, F., Sinulingga, M.B. dan Jati, W.N. 2005. Kajian Awal Pemanenan Siput Laut (Gastropoda) di Pantai Krakal Yogyakarta: II. Aktivitas Pemanenan. Biota, X (1): 24-30.

Zardus, J.D. dan Martel, A.L. 2002. Phylum Mollusca: Bivalvia. In: Young, C.M., Sewell, M.A. \& Rice, M.E. (Eds.). Atlas of marine invertebrates larva. Pp. 289-301.Academic Press, San Diego, USA. 